\title{
E-commerce Distribution Network Optimization Research Based on B2C
}

\author{
Xiao Qing Bi ${ }^{1, \text { a }}$, Chao Liu ${ }^{2, b}$ \\ ${ }^{1}$ College of Management, School of Tianjin University of Technology, Tianjin 300384, China \\ ${ }^{2}$ College of Management, School of Tianjin University of Technology, Tianjin 300384, China \\ aemail:851795839@qq.com, bemail:851795839@qq.com
}

Keywords: e-commerce distribution, site selection, distribution cost, heuristic algorithm, Taboo search algorithm

\begin{abstract}
This paper studies the distribution center location, transit center location and last-mile distribution strategy in the e-commerce distribution network optimization under B2C environment. Considering the optimization of distribution network from the cost and structure the combination about distribution node. The distribution model takes the system total cost least as the target function. Based on the existing references, Initial assignment algorithm is used based on heuristic rules and taboo search optimization algorithm to solve the model.
\end{abstract}

\section{Introduction}

Facing the huge E-commerce logistics distribution amount and the increasingly soaring customers requirements to the distribution timeliness and service quality about E-commerce, E-commerce enterprises and other network sales enterprises, express enterprises and third parties logistics enterprises improve the traditional door-to-door service quality, but also continue to increase the construction of terminal distribution network. Each enterprises build the package self-help station, develop self-help service considering consumer needs personalized and make the most use of social resource, the aim is to break through the problems of low efficiency, high cost and poor service quality of terminal distribution. Distribution center and transit center of key nodes are arranged by e-commerce enterprises and logistics enterprises one after another, try to regard it as the core competence of the enterprise.

B2C E-commerce distribution problem is a multi-objective function that takes into account the location of region distribution center, the distribution of demand points and the distribution of parcels in region distribution center to minimize the logistics cost, the shortest delivery time and the greatest customer satisfaction. The location problem of distribution center and transit center is a logistics facility location problem, which has been studied more. Aikens et al. [1] studied a variety of location models and concluded that the problem characteristics determine the choice of model. Tsao et al. [2] adopted non-linear programming method to solve the problem of logistics cost considering the location of regional distribution center, demand point allocation and regional distribution center inventory strategy. Wang et al. [3] studied the situational advantages of the three delivery modes of delivery based on the vehicle routing model, acceptance and self-service, and analyzed its operational efficiency. Hayel et al. [4] firstly introduce customer limited rationality into terminal distribution, and consider that customers are prone to make mistakes in the decision of self-delivery and door-to-door service when the system information is not complete, and use competitive queue to simulate customer's choice of distribution service, consider the cost of the transfer of the package and the cost of delivery and congestion. LD Burns et al. [5] studied the distribution Strategies that Minimize Transportation and Inventory Costs, develops an analytic method for minimizing the cost of distributing freight by truck from a supplier to many customers, the conclusion says that the cost trade-off in different strategies depend on shipment size.

Logistics is the basis of the development of e-commerce. Reasonable logistics distribution scheme can greatly improve the competitiveness of logistics enterprises. The existing literature mainly focuses on the study of transit center location and optimization algorithm design. This paper 
constructed e-commerce distribution multi-level node cost estimation model, evaluated the cost of several nodes in the distribution process from the systematic perspective, and then integrated the distribution network from the holistic perspective, optimize the existing distribution network.

\section{Problem description and modeling}

\subsection{Problem description}

The e-commerce distribution problem is a multi-level multi-node distribution problem, including the transit center and the last mile distribution node from the urban distribution center to the terminal customer. The urban distribution center undertakes the functions of inventory, packaging, sorting, transportation and even circulation and processing. The last mile distribution patterns include the parcel self-service station, self-service cabinet and other forms. Urban distribution centers generally use light truck transportation, transit center to the last mile distribution station use tricycles, vans and electric vehicles for distribution. The total cost of the whole distribution process includes the transportation cost from the urban distribution center to the transit center, the node operation cost and the distribution cost from the transit center to the last mile distribution station. In a distribution cycle, considering the capacity of each node and the amount of single distribution, the remains of node and the cost of its holding. The minimization of the node joint operation cost is the goal of e-commerce distribution network optimization.

\subsection{Modeling}

\subsubsection{Model assumptions}

To evaluate the economy of the model, the following assumptions can be made:

(1) The scale effect exists in the operation cost of the node, that is, the increase of the cost and the change of the amount of the package are in non-linear synchronization, which can be considered as the normal distribution of the service.

(2) The distribution distance between nodes adopts approximate algorithm: Daganzo thinks that vehicle distribution distance is related to the density of terminal demand point and the average distance between transit center and terminal demand point. The relationship between the total vehicle running distance $\mathrm{Li}$ of the transit center $\mathrm{i}$ and the number of terminal demand points $\mathrm{N}$ can be expressed as follows:

$$
\frac{L_{\mathrm{i}}}{N_{\mathrm{i}}} \cong 1.8 \overline{\rho_{\mathrm{i}}}\left[(1.1 / \mathrm{C})+\left(0.83 / \sqrt{N_{\mathrm{i}}}\right)\right]
$$

(3) Delivery of packages can be in place on time according to the requirements in the distribution cycle ;

(4) The cost of transportation shall be borne by the seller.

\subsubsection{Sets and parameter settings}

$\mathrm{J}_{\mathrm{i}}$ : Total number of nodes forming the entire distribution network; $(\mathrm{i}=1,2,3)$

$\mathrm{J}_{1}$ : Distribution center collection;

$\mathrm{J}_{2}$ : Transfer center collection;

$\mathrm{J}_{3}$ : Collection of last mile distribution stations;

$\bar{N}(\mathrm{j})$ : j Distribution of parcels collection;

$\bar{M}(\mathrm{~m})$ :M Collection of packages arranged by m;

$\mathrm{b}_{\mathrm{n} \sim \mathrm{Ji}}$ : The maximum transit capacity of $\mathrm{J}_{\mathrm{i}}$;

$\mathrm{q}_{\mathrm{n} \sim \mathrm{Ji}}$ : Maximum capacity of $\mathrm{J}_{\mathrm{i}}$;

$\mathrm{e}_{\mathrm{m} \sim \mathrm{mj}}$ : the maximum loading capacity $\mathrm{m} \sim \mathrm{by} \mathrm{j}$ to $\mathrm{m}$;

$\mathrm{S}_{\mathrm{n} \sim \mathrm{Ji}}$ : The fixed cost of node $\mathrm{J}_{\mathrm{i}}$ distribute $\mathrm{n} \sim$;

$\mathrm{P}_{\mathrm{n} \sim \mathrm{j}}$ : Variable distribution cost of unit package $\mathrm{n} \sim$ at node $\mathrm{J}_{\mathrm{i}}$;

$\mathrm{I}_{\mathrm{n} \sim \mathrm{Ji}}$ :The storage cost of unit package $\mathrm{n} \sim$ in $\mathrm{J}_{\mathrm{i}}$; 
$\mathrm{C}_{\mathrm{m} \sim \mathrm{ji}}$ : The transport cost of unit package $\mathrm{m} \sim$ between nodes;

$\mathrm{d}_{\mathrm{n} \sim \mathrm{ji}}$ : The package amount that downstream node can accept the upstream node;

$\overline{\mathrm{d}}_{\mathrm{n} \sim \mathrm{ji}}$ : The number of packages arranged by upstream nodes to downstream nodes;

$\mathrm{p}_{\mathrm{n} \sim \mathrm{ji}}$ : unit distribution price that $\mathrm{J}_{\mathrm{i}} \mathrm{n} \sim$ parcel delivery, since it is a random variable varying with the number of variables, it can be approximately regarded as obedience $\mathrm{P}_{\mathrm{n} \sim \mathrm{Ji}_{\mathrm{i}}} \sim \mathrm{N}\left(\mu_{\mathrm{p}}, \delta_{\mathrm{p}}{ }^{2}\right)$.

\subsubsection{Decision variables}

$\mathrm{u}_{\mathrm{n} \sim \mathrm{j}}= \begin{cases}1, & \mathrm{~J}_{\mathrm{i}} \text { delivery package } \mathrm{n} \sim \\ 0, & \text { or }\end{cases}$

$\mathrm{x}_{\mathrm{n} \sim \mathrm{j}}$ : The batch of $\mathrm{n} \sim$ at node $\mathrm{J}_{\mathrm{i}}$;

$\mathrm{y}_{\mathrm{n} \sim \mathrm{i}}$ : The storage of node $\mathrm{J}_{\mathrm{i}}$;

$\mathrm{Z}_{\mathrm{m} \sim \mathrm{Ji}}$ : Bulk distribution of package $\mathrm{m} \sim$ between node $\mathrm{J}_{\mathrm{i}}$.

\subsubsection{Cost estimation model for joint distribution of e-commerce distribution nodes}

Based on the description of the problem, the relevant assumptions and the definition of each parameter, the following economic evaluation methods can be established for the distribution model (cost minimization method):

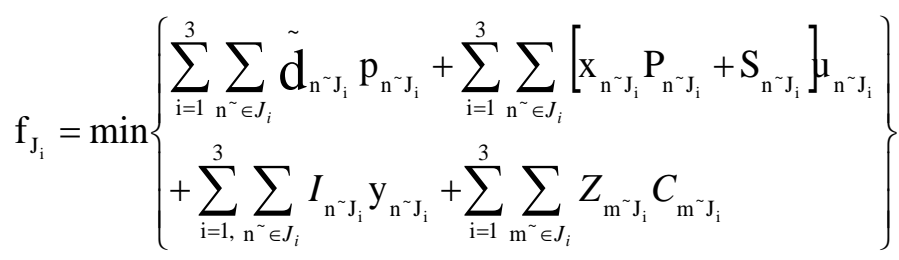

$$
\begin{aligned}
& \text { s.t. } \quad \tilde{\mathrm{d}}_{\mathrm{n}^{\sim} \mathrm{J}_{\mathrm{i}}}=\mathrm{d}_{\mathrm{n}^{\sim} \mathrm{J}_{\mathrm{i}}} \\
& \mathrm{x}_{\mathrm{n}^{\sim} J_{\mathrm{i}}} \leq \mathrm{b}_{\mathrm{n}^{\sim} \mathrm{J}_{\mathrm{i}}} \\
& \mathrm{y}_{\mathrm{n}^{\sim} J_{\mathrm{i}}} \leq \mathrm{q}_{\mathrm{n}^{\sim} \mathrm{J}_{\mathrm{i}}} \\
& Z_{\mathrm{m}^{\sim} \mathrm{J}_{\mathrm{i}}} \leq \mathrm{e}_{\mathrm{m}^{\sim} \mathrm{J}_{\mathrm{i}}} \\
& \mathrm{x}_{\mathrm{n}^{\sim} \mathrm{J}_{\mathrm{i}}} \mathrm{y}_{\mathrm{n}^{\sim} \mathrm{J}_{\mathrm{i}}} \mathrm{Z}_{\mathrm{m}^{\sim} \mathrm{J}_{\mathrm{i}}} \geq 0 \mathrm{u}_{\mathrm{n}^{\sim} \mathrm{J}_{\mathrm{i}}} \in\{0,1\}
\end{aligned}
$$

Above: In the (1), all the parentheses express the cost of all parcels in the distribution period, the total variable distribution cost of all packages, the total cost of all parcels and the total transportation cost of all packages in j. Formula (2) represents the balance of the volume of packages arranged between upstream nodes and downstream nodes; Formula(2) means Ji's ability to deal with the package $n \sim$;Formula (4) means that Ji's ability on the package $\mathrm{n} \sim$ storage capacity ;Formula (5) means that Ji's ability constraints on the transport capacity of the package $\mathrm{m} \sim$;Formula (6) denotes the non-negative and 0-1 conditions of decision variables.

\section{Model solving}

For solving the model, current scholars mainly adopted the combination of intelligent algorithm and heuristic algorithm. Yang Jun et al. [6] used Taboo search algorithm, Eiichi Taniguchi et al. [7] adopted queuing theory and nonlinear programming techniques to determine the best solution of the optimal size and the location of public logistics terminals, Guan Fei et al. [8] used the nondominated sorting genetic algorithm to Select reasonable location of logistics distribution center. This paper adopted the initial allocation algorithm based on heuristic rules and the Taboo search hybrid optimization algorithm to solve the model. 


\subsection{Initial assignment algorithm based on heuristic rules}

To allocate the terminal demand points by the heuristic rules of terminal demand point distribution amount and distribution distance ratio from large to small.

(1) Measuring the distance between the open transit center and the terminal demand point $r_{i j}$.

(2) Calculation matrix $\bar{d}_{n^{\sim} J i} / r_{\mathrm{ij}}$,note $B=\left[\begin{array}{ccc}b_{11} & \mathrm{~L} & b_{1 n} \\ \mathrm{M} & 0 & \mathrm{M} \\ b_{m 1} & \mathrm{~L} & b_{\mathrm{mn}}\end{array}\right]$

,rows represent $\mathrm{m}$ open transit

centers,lists show all the $\mathrm{n}$ end demand points.

(3)Take the maximum value of $b_{i^{\prime}{ }^{\prime}}$ in matrix $B, b_{i}{ }^{\prime}{ }^{\prime}$ indicate that the terminal requirement point $j^{\prime}$ wants to allocate node i',When checking that the residual capacity of the node can satisfy the terminal requirement point j.If yes, assign the terminal requirement point $j$ ' to node $i$, at the same time, delete the column of the terminal requirement point $j^{\prime}$, or set $b_{i^{\prime} j}$ ' to zero.

(4)Repeat (3)until all terminal demand points are assigned to the transit center, generate an initial delivery scheme.

\subsection{Optimal assignment algorithm based on Taboo search algorithm}

First define two operations "move" and "swap". Take A and B for example,"move" refers to one or several end points service by node A need change to node B;"swap" means that the end requirements of the node $\mathrm{A}$ are interchanged with the end requirements that belong to the node $\mathrm{B}$.

(1) Generate the distance table between the determination node and the end requirement point.

(2) "move" operation. Select two determined nodes A and B randomly, calculate the distance between the terminal requirement point which serviced by node $\mathrm{A}$ and the transit center $\mathrm{B}$, change the minimum demand point to node $B$ service, and judge whether the ability constraint of node $B$ can be satisfied. If not satisfied, perform the "move" operation.

(3) "swap" operation. select two nodes A and B randomly, calculate the nearest distance from node $B$ to the end requirement point serviced by node $A$. And the nearest distance between the end requirement point of node $B$ service and node $A$. Switch each of the nearest demand point to node $A$ and node $\mathrm{B}$ and determine whether the terminal total demand exceeds the delivery capacity constraint.

(4) When the candidate solution satisfy the contempt rule, use the best state of the contempt criterion instead the current state to be the new current solution, and use the Taboo object corresponding to the original state to replace the earliest taboo object that enters the Taboo list, and then the Tabu object enters the Tabu Table and turns to (6), otherwise, turns to (5).

(5) Judge the taboo attribute of each object corresponding to the candidate solution, choose the best state corresponding to the non-taboo object in the candidate solution set as the new current solution, meanwhile, replace the earliest Taboo objects with the corresponding Taboo objects.

(6)Determine the termination condition, if so, stop, or turn (2).

\section{Conclusion}

In this paper, the e-business distribution network is divided into several interconnected nodes, and the effectiveness of the distribution network is evaluated through the joint evaluation of the economic performance of the network nodes. Constructed the analysis model of distribution network, and based on the former existing literature, we use the initial allocation algorithm based on heuristic rule and taboo search algorithm to calculate the model, and optimize the delivery cost of distribution network. The shortcoming of this paper is that there is no case study on the algorithm, only the results are analyzed based on the existing literature, and discussed the feasibility of the 
evaluation method theoretically.

\section{References}

[1] Aikens CH. Facility location models for distribution planning [J]. European Journal of Operational Research,1985,22(3):263-279

[2] Tsao YC, Mangorta D, Lu JC, et al. A continuous approximation approach for the integrated facility-inventory allocation problem [J]. European Journal of Operational Research, 2012, 22 (2):216-228

[3] Wang Yong, Ma Xiaolei, Xu Maozeng, et al. Two-echelon logistics distribution region partitioning problem based on a hybrid particle swarm optimization-genetic algorithm[J]. Expert Systems with Application, 2015,42(12):5019-5031

[4] Hayely, Quadrid, JIM Nezt, et al. Decentralized optimization of last-mile delivery services with non-cooperative bounded rational customers [J]. Annals of Operations Research, 2016, 239(2):451-469

[5] Burns, L. D., Hall, R. W., Blumenfeld, D. E., \& Daganzo, C. F. (1985). Distribution strategies that minimize transportation and inventory costs. Operations Research, 33(3), 469-490.

[6] Yang Jun, Lu Wei. Multi - capacity Class Location and Delivery Problem Study under Low Carbon Policy[J]. Chinese Journal of Management Science, 2014,20(12):3140-3149

[7] Eiichi Taniguchi, Michihiko Noritake, Tadashi Yamada, Toru Izumitani. Optimal size and location planning of public logistics terminals[J]. Transportation Research Part E, 1999, 35(3).

[8] Guan Fei, Zhang Qiang. Fuzzy multi - objective logistics distribution center location model and its solution algorithm[J]. Chinese Journal of Management Science,2013,21(S1):57-62 